\title{
Luminescence dating of neotectonic activity on the southwestern coastal plain, Taiwan
}

\author{
Y.W. Chen ${ }^{\mathrm{a}, \mathrm{b}, *}$, Y.G. Chen ${ }^{\mathrm{a}}$, A.S. Murray ${ }^{\mathrm{b}}$, T.K. Liu ${ }^{\mathrm{a}}$, T.C. Lai ${ }^{\mathrm{c}}$ \\ ${ }^{a}$ Department of Geosciences, National Taiwan University, No. 1, Sec. 4, Roosevelt Road, Taipei 106, Taiwan, Republic of China \\ ${ }^{\mathrm{b}}$ Department of Earth Sciences, The Nordic Laboratory for Luminescence Dating, University of Aarhus, Risø National Laboratory, \\ DK-4000 Roskilde, Denmark \\ ${ }^{\mathrm{c}}$ Central Geological Survey, MOEA, No. 2, Lane 109, Hua-Hsin St., Chung-Ho, Taipei 235, Taiwan, Republic of China
}

\begin{abstract}
The southwestern coastal plain of Taiwan is heavily urbanised, with a population of more than 6 million. The area is known to be subsiding, and the resulting basin is filled with thick fluvial deposits, of at least $200 \mathrm{~m}$ thickness. In the past century, three large earthquakes have occurred in the area; two caused surface ruptures, and resulted in large property loss and more than 2000 casualties. There is an urgent need for an understanding of the dynamics and recurrence intervals of this neotectonic activity, but little is known of the chronology of the late Pleistocene deposits. Recently more than 20 cores longer than $250 \mathrm{~m}$ were taken from the coastal plain as part of a large hydrogeological investigation, and basic data on lithology, hydrogeology and palaeobiology were collected. The base of these cores is beyond the ${ }^{14} \mathrm{C}$ age limit, and so the application of luminescence dating to these sediments has been investigated.

Optically stimulated luminescence methods have been applied to quartz sand-sized grains extracted from 29 samples. Dosimetry based on gamma spectrometry is also compared with ICP-MS and XRF analyses. In the age range up to $\sim 40 \mathrm{ka}$, radiocarbon ages are compared with the luminescence results, to give confidence that the initial bleaching of these sediments was sufficient. The luminescence ages are then discussed and differential rates of basin subsidence are deduced. It is clear from these data that the study area is tectonically active, and it may be that regions of similar subsidence rate correlate with identifiable geological structures. (C) 2003 Elsevier Science Ltd. All rights reserved.
\end{abstract}

\section{Introduction}

Taiwan (Fig. 1) is a fold and thrust belt resulting from the arc-continent collision between the Phillipine Sea plate and the Eurasia Continental plate. Mountain building is taking place on the eastern side of the island; the sedimentary sequence deposited on western continental shelf is forced to stack up by imbricated and west-vergent thrusts (Ho, 1982; Teng, 1990). The foreland area to the west is constantly being filled with fluvial sediments derived from the eastern mountains. Thus the accumulation rates in the sedimentary basin are mainly controlled by tectonic activity in the west of the island (Deffontaines et al., 1997). To help provide chronological control for the neotectonics of the southwestern coastal plain, luminescence dating has been applied to fluvial sediments from the plain. The

*Corresponding author. Tel.: +886-2-23697647; fax: +886-223636095.

E-mail address: f90224212@ntu.edu.tw (Y.W. Chen). luminescence characteristics are first presented, and the resulting luminescence ages are compared with ${ }^{14} \mathrm{C}$ ages up to about $40 \mathrm{ka}$. The chronology is then discussed in terms of stratigraphy and sedimentary accumulation rates.

\section{Sampling sites and experimental treatment}

Luminescence dating was applied to sand-sized quartz extracted from five cores taken from various locations in the sedimentary basin (Fig. 1). Three cores [Shihfen (SF), Tawen (TW), and Tsungyeh (TY)] along the Tsengwenhsi were used to investigate the possible importance of fluvial environment, and preliminary tests of the trend in tectonic activity parallel to the Western Foothills were examined using a further two cores [Hsinkang (HK) and Machouhou $(\mathrm{MCH})$ compared with Tsungyeh (TY)]. The top layers of all cores lay between 2 and $12 \mathrm{~m}$ above sea level; 29 samples from various depths were examined in total. 


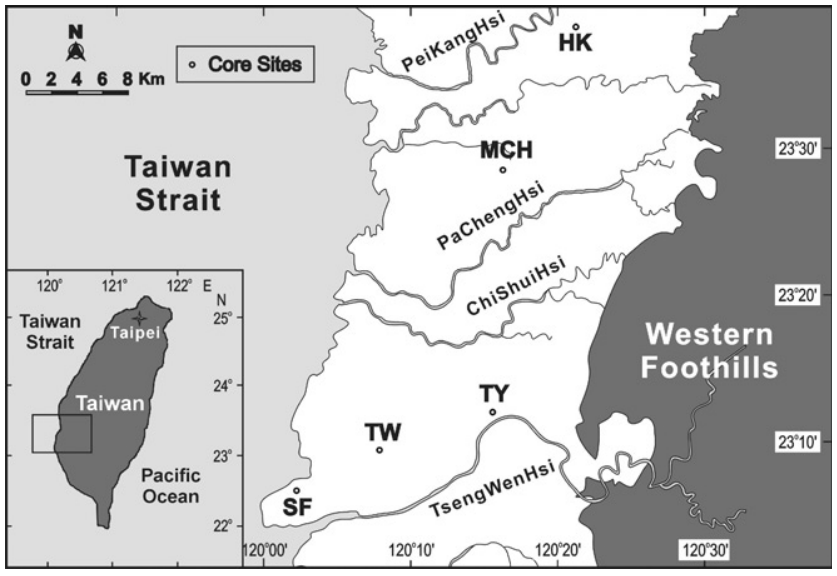

Fig. 1. Sample location of core sites (open circles). The cores [SFShihfen, TW-Tawen, TY - Tsungyeh, MCH-Machouhou, HKHsinkang] were taken by the Central Geological Survey for the project "Groundwater monitoring Network in Taiwan".

The single-aliquot regenerative (SAR) dose protocol (Murray and Wintle, 2000) was applied to large aliquots (about 5000 grains) of $90-112 \mu \mathrm{m}$ quartz, which were cleaned using $\mathrm{HCl}, \mathrm{H}_{2} \mathrm{O}_{2}$ and $\mathrm{HF}$ in the usual way, and checked with IR stimulation for feldspar contamination. Radionuclide concentrations were measured using highresolution gamma spectrometry, ICP-MS and XRF. These radionuclide concentrations were converted to dose rates using the data presented in Olley et al. (1996), and the cosmic ray contribution was estimated for the appropriate altitude, latitude, longitude, and depth (Prescott and Hutton, 1988, 1994).

All measurements were undertaken using a Risø TL/ OSL reader with blue $(470 \mathrm{~nm})$ light stimulation, and luminescence detection was through $7 \mathrm{~mm}$ of U-340 filters (Bøtter-Jensen et al., 2000).

\section{Luminescence characteristics}

\subsection{Preheat and cutheat plateaus}

To determine the appropriate thermal pretreatments in the SAR protocol (Table 1), preheat and cutheat plateaus were carried out for two representative samples, SF212.5m and HK249.7m. The preheat plateaus are shown in Fig. 2 together with typical stimulation decay curves (inset). Both samples showed an apparently constant $D_{\mathrm{e}}$ in the temperature interval 220 $280^{\circ} \mathrm{C}$; the relevant recycling ratios $\left(R_{5} / R_{1}\right)$ were all close to unity $(1.018 \pm 0.015$ and $1.014 \pm 0.013$, respectively), and recuperation was small compared to the natural signal $\left(R_{4} / N<4 \%\right)$; a preheat temperature of $260^{\circ} \mathrm{C}$ (step 2 in Table 1) was selected for all further work.
Table 1

Single-aliquot regenerative dose (SAR) protocol (Murray and Wintle, 2000)

\begin{tabular}{lll}
\hline Step & Treatment & Observed \\
\hline $1^{\mathrm{a}}$ & Give dose, $D_{i}$ & - \\
$2^{\mathrm{b}}$ & Preheat $260^{\circ} \mathrm{C}$ for $10 \mathrm{~s}$ & - \\
3 & Stimulate for $40 \mathrm{~s}$ at $125^{\circ} \mathrm{C}$ & $L_{i}$ \\
4 & Give test dose, $D_{\mathrm{t}}$ & - \\
$5^{\mathrm{b}}$ & Heat to $180^{\circ} \mathrm{C}$ & - \\
$6^{\mathrm{c}}$ & Stimulate for $40 \mathrm{~s}$ at $125^{\circ} \mathrm{C}$ & $T_{i}$ \\
$7^{\mathrm{d}}$ & Return to 1 & - \\
\hline
\end{tabular}

${ }^{\mathrm{a}}$ For the natural sample, $i=0$ and $D_{0}$ is the natural dose.

${ }^{\mathrm{b}}$ Aliquot cooled to $<60 \mathrm{C}$ after heating.

${ }^{\mathrm{c}} L_{i}$ and $T_{i}$ are derived from the stimulation curve, taking the first $0.8 \mathrm{~s}$ of the initial OSL signal, minus a background estimated from the last $4.0 \mathrm{~s}$ of the OSL signal.

${ }^{\mathrm{d}} N=L_{0} / T_{0}, R_{i}=L_{i} / T_{i}(i=1-5)$.

Fig. 3 presents cutheat plateaus for the same two samples using a fixed preheat of $260^{\circ} \mathrm{C}$. No temperature dependence is observed between $180^{\circ} \mathrm{C}$ and $240^{\circ} \mathrm{C}$; a cutheat of $180^{\circ} \mathrm{C}$ (step 5 in Table 1) was selected for further work.

\subsection{Growth curves}

Because we are interested in dating samples well beyond the ${ }^{14} \mathrm{C}$ range in a moderately high dose rate environment $\left(\sim 2.5 \mathrm{~Gy} \mathrm{ka}^{-1}\right)$, it is important to investigate the upper limit to the dose that can be measured before saturation of the luminescence signal. Fig. 4 presents growth curves for aliquots from each of two samples, SF $212.5 \mathrm{~m}$ and HK249.7m. In both cases, recycling at both high and low doses is excellent (see open circles), and both growth curves pass very close to the origin (open triangles). It is clear from these data that a natural dose of $>500 \mathrm{~Gy}(\approx 200 \mathrm{ka})$ could be measured before saturation significantly complicates the analyses.

The relevant dose distributions, each obtained from 36 aliquots, are shown inset to Fig. 4; the distributions do not show significant skewness, and relative standard deviations are about $10 \%$, providing relative standard errors on the dose of $<2 \%$ using 36 aliquots.

\subsection{Thermal transfer and dose recovery tests}

The importance of thermal transfer of charge into the OSL trap as a result of preheating (Rhodes, 2000; Wintle and Murray, 2000) was investigated using aliquots stimulated twice at room temperature with more than $2 \mathrm{~h}$ delay between stimulation (to ensure complete emptying of the rapidly bleached OSL trap). All subsequently measured apparent values of $D_{\mathrm{e}}$ were less than $1 \mathrm{~Gy}$ for preheat temperatures from $180^{\circ} \mathrm{C}$ to $300^{\circ} \mathrm{C}$. This is small compared with typical natural 


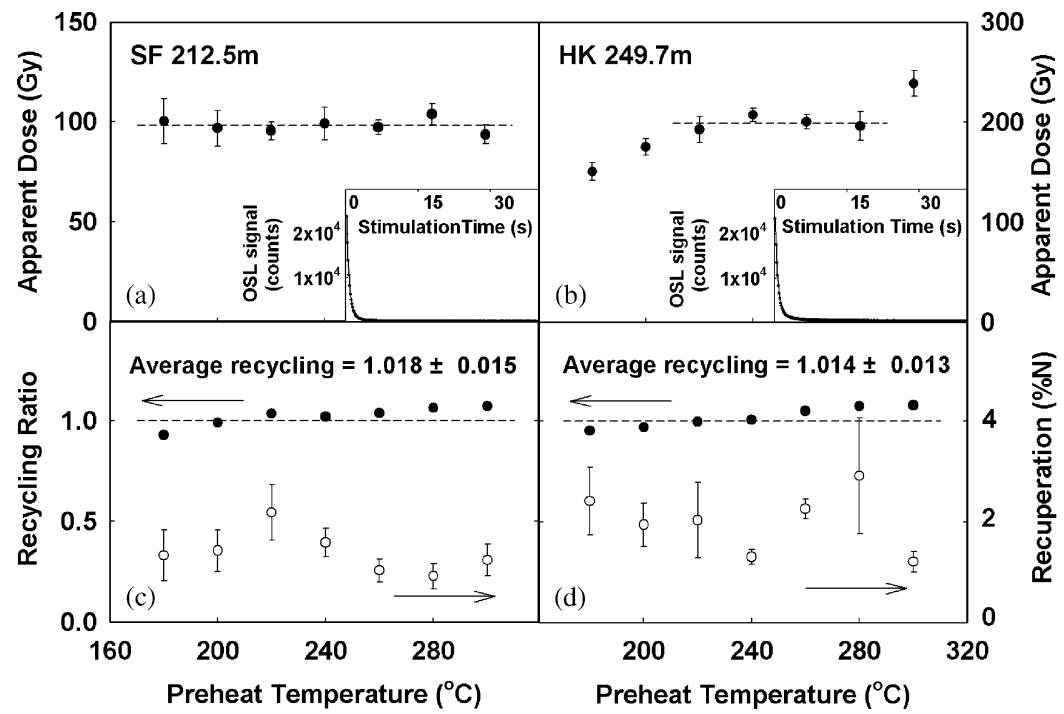

Fig. 2. Preheat plateau for SF212.5m (a) and (c) and HK249.7m (b) and (d). The upper part of this figure shows the preheat plateau with three aliquots for each preheat temperature from $180^{\circ} \mathrm{C}$ to $300^{\circ} \mathrm{C}$, and the lower part is the average of the recycling ratio $\left(R_{5} / R_{1}\right)$ and recuperation $\left(R_{4} / N\right)$ at different preheat temperatures. The cutheat temperature was fixed at $180^{\circ} \mathrm{C}$.

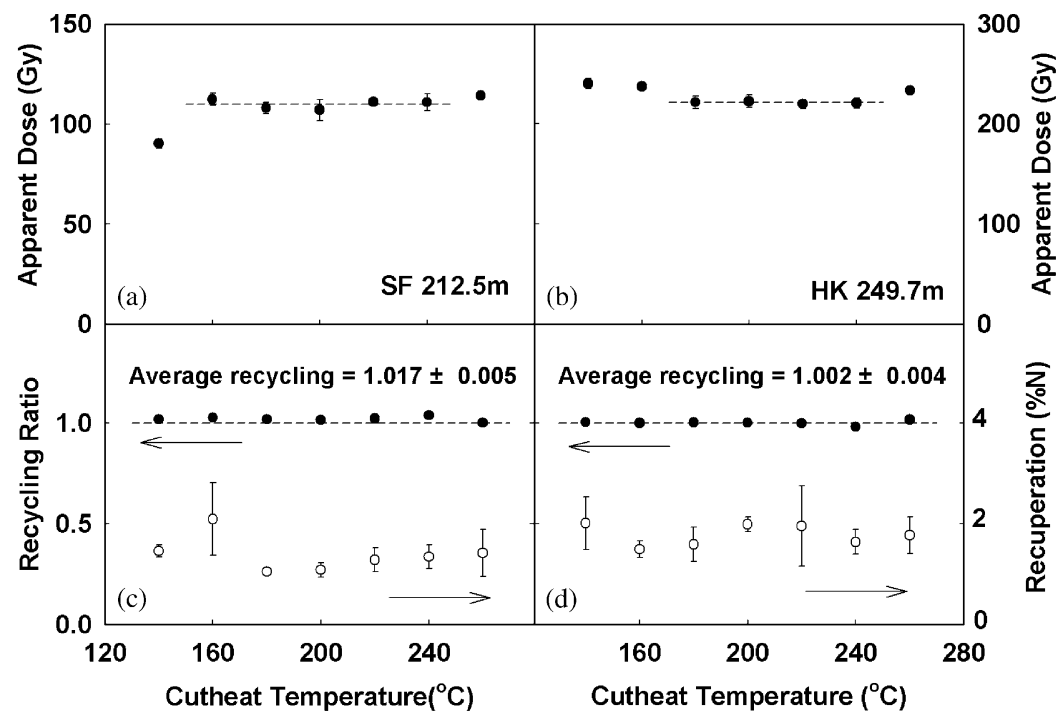

Fig. 3. Cutheat plateau for SF2 $12.5 \mathrm{~m}$ (a) and (c) and HK249.7m (b) and (d). Cutheats from $140^{\circ} \mathrm{C}$ to $260^{\circ} \mathrm{C}$ were chosen with three aliquots used at cutheat temperature; the preheat temperature was fixed at $260^{\circ} \mathrm{C}$.

doses, and we conclude that thermal transfer is not a likely source of uncertainty in these samples.

Finally, we tested our ability to accurately measure a known dose given to a sample without prior heating. Although not a comprehensive check of the ability of SAR to measure the natural dose in these samples, this dose recovery test does provide a method to determine whether the overall effects of sensitivity changes (arising from possible changes in both electron trapping probability and luminescent recombination probability) have been properly corrected for. Twelve aliquots of five samples [SF212.5m, TW166.8m, TY195.9m, $\mathrm{MCH} 203.2 \mathrm{~m}$, and $\mathrm{HK} 249.7 \mathrm{~m}$ ] were bleached at room temperature as above, before being given a known beta dose. The latter dose was then measured using a routine
SAR sequence. Representative results (for samples TW166.8m and TY195.9m) are shown in Fig. 5, together with the recycling ratios $\left(R_{5} / R_{1}\right)$. The average ratio of observed to given dose for those samples was $1.054 \pm 0.006$, indicating that we were able to measure the given dose to within $6 \%$, on average.

\section{Luminescence ages and discussion}

\subsection{Dose rates and ages}

A comparison of 20 total dose rates derived from ICP-MS (for uranium and thorium concentration) and $\mathrm{XRF}$ (for potassium concentration) with those from 


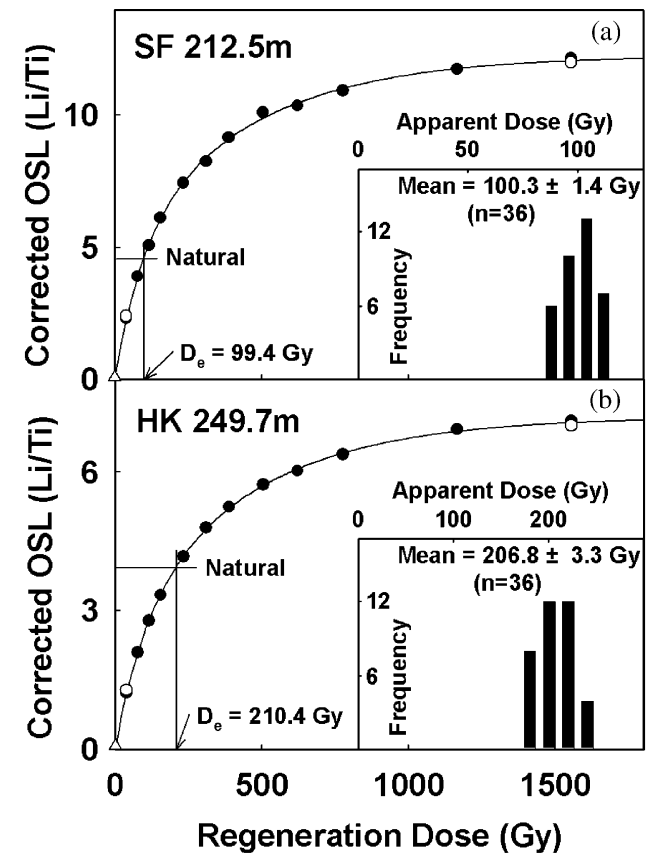

Fig. 4. Growth curve with dose distribution for SF212.5m(a) and HK $249.7 \mathrm{~m}(\mathrm{~b})$. The SAR protocol was using 12 different regenerative doses. The first last regenerative dose were repeated twice (open circles) and step 4 of the (Table 1) shows recuperation close to zero as open triangles. The test doses used for these two samples were 11.7 and 23.3 Gy. Dose distributions are shown inset.

high resolution gamma spectrometry is shown in Fig. 6. The same water content corrections and cosmic ray dose rates have been included in both data sets, and dose rates vary in the range from 1.8 to $3.3 \mathrm{~Gy} \mathrm{ka}^{-1}$. The comparison is considered acceptable, but the slope of the regression line passing through the origin is $0.91 \pm 0.08$, indicating a possible tendency for chemical analysis to underestimate compared with gamma spectrometry. The scatter is significant, the relative standard deviation of the ratio is $7 \%$. Table 2 summarises the estimates of $D_{\mathrm{e}}$, and the total dose rates based on gamma spectrometry, assuming the saturation water content has applied throughout the lifetime of the site. We selected the gamma spectrometry results because these average over larger samples, $\sim 100 \mathrm{~g}$ compared with $\sim 0.4 \mathrm{~g}$ for ICP-MS and XRF. The final column of Table 2 lists the resulting OSL ages.

\subsection{Comparison with stratigraphy}

The OSL ages are compared with ${ }^{14} \mathrm{C}$ ages on the stratigraphic columns (Fig. 7). Most OSL ages are consistent with those from ${ }^{14} \mathrm{C}$ but there is one disagreement in the Shihfen core (SF) at the depth of $117.4 \mathrm{~m}$. Here an OSL age of $21.2 \pm 1.3 \mathrm{ka}$ lies between ${ }^{14} \mathrm{C}$ ages of $12.5-12.7 \mathrm{ka}$ and $13.1-13.9 \mathrm{ka}$. From an examination of the dose rate and $D_{\mathrm{e}}$ in this case, the anomaly is probably caused by the dose rate, which is

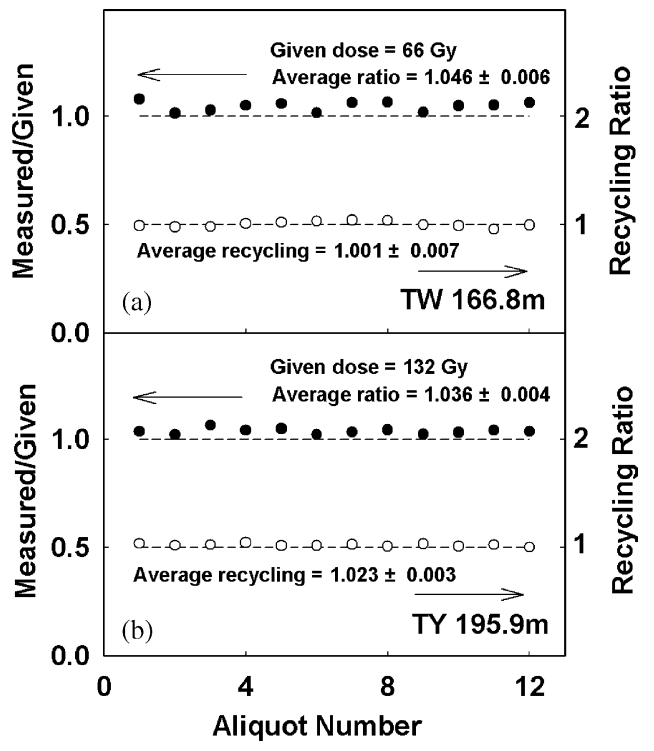

Fig. 5. Dose recovery test for TW166.8m(a) and TY195.9m(b). Twelve aliquots of each sample were measured using a $260^{\circ} \mathrm{C}$ preheat and $180^{\circ} \mathrm{C}$ cutheat temperature. The given dose was selected to be close to the equivalent dose. The ratios of measured to given dose are shown as filled circles, and the recycling ratios $\left(R_{5} / R_{1}\right)$ of each aliquot as open circles.

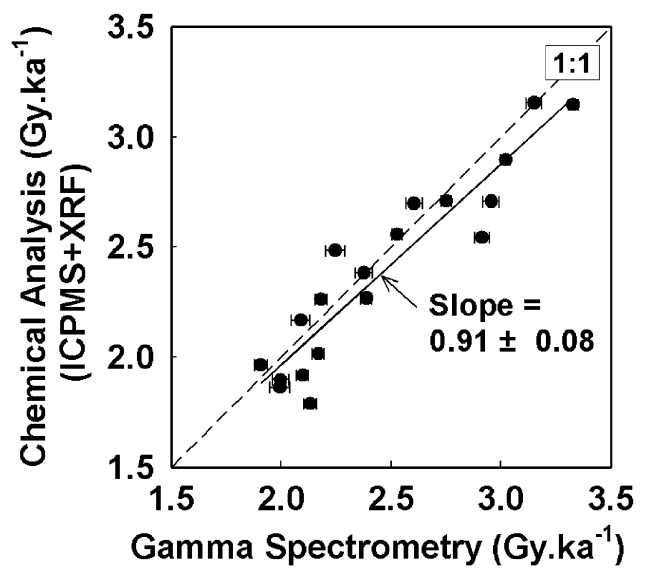

Fig. 6. Comparison of the dose rate derived from gamma spectrometry and chemical analyses (ICP-MS + XRF) for 20 samples.

abnormally lower than that above and below. If the average of the adjacent two dose rates is used instead, the age falls to about $15 \mathrm{ka}$, consistent with the ${ }^{14} \mathrm{C}$ data and the other OSL ages. Another marked anomaly occurs at the middle of the Hsinkang core (HK) at about $83 \mathrm{~m}$. The age at $82.9 \mathrm{~m}(69 \pm 4 \mathrm{ka})$ and $83.6 \mathrm{~m}(76 \pm 4 \mathrm{ka})$ are much older compared with the ages above $(23.9 \pm 0.8 \mathrm{ka})$ and below $(51.2 \pm 1.9 \mathrm{ka})$. Using the average of the dose rates from above and below these two samples gives ages of about 57 and $55 \mathrm{ka}$, consistent with the overall stratiography. Although this does not 
Table 2

OSL ages and the total dose rates from gamma spectrometry

\begin{tabular}{|c|c|c|c|c|c|}
\hline Code $^{\mathrm{d}}$ & Equivalent dose $^{\mathrm{a}}$ (Gy) & $(n)$ & 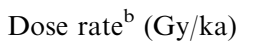 & Water content $\mathrm{c}^{\mathrm{c}}(\%)$ & Age (ka) \\
\hline SF84.8 & $28.7 \pm 0.5$ & 18 & $3.15 \pm 0.12$ & 19 & $9.1 \pm 0.4$ \\
\hline SF 100.6 & $30.2 \pm 0.5$ & 22 & $3.01 \pm 0.08$ & 25 & $10.0 \pm 0.4$ \\
\hline SF 117.4 & $44.0 \pm 1.3$ & 33 & $2.13 \pm 0.09$ & 28 & $20.6 \pm 1.2$ \\
\hline SF187.9 & $96.9 \pm 1.9$ & 18 & $2.91 \pm 0.11$ & 36 & $33.3 \pm 1.6$ \\
\hline SF212.5 & $99.1 \pm 1.2$ & 36 & $2.25 \pm 0.12$ & 18 & $44 \pm \overline{3}$ \\
\hline TW86.9 & $22.1 \pm 0.3$ & 18 & $2.38 \pm 0.11$ & 28 & $9.3 \pm 0.5$ \\
\hline TW121.9 & $24.0 \pm 0.5$ & 18 & $1.91 \pm 0.10$ & 27 & $12.6 \pm 0.7$ \\
\hline TW166.8 & $69.4 \pm 1.5$ & 18 & $2.09 \pm 0.12$ & 25 & $33 \pm \overline{2}$ \\
\hline TW245.1 & $107.2 \pm 1.2$ & 18 & $1.91 \pm 0.12$ & 22 & $56 \pm 4$ \\
\hline TY79.5 & $34.1 \pm 0.5$ & 18 & $2.61 \pm 0.11$ & 24 & $13.1 \pm 0.6$ \\
\hline TY 100.8 & $53.5 \pm 0.6$ & 36 & $2.10 \pm 0.09$ & 25 & $25.5 \pm 1.3$ \\
\hline TY140.0 & $120 \pm \overline{2}$ & 29 & $3.00 \pm 0.08$ & 30 & $40.1 \pm 1.5$ \\
\hline TY195.9 & $132.5 \pm 0.4$ & 32 & $2.17 \pm 0.09$ & 26 & $61 \pm \overline{3}$ \\
\hline MCH35.2 & $24.3 \pm 0.5$ & 18 & $2.53 \pm 0.08$ & 33 & $9.6 \pm 0.4$ \\
\hline МCH79.3 & $139 \pm \overline{3}$ & 18 & $3.33 \pm 0.08$ & 20 & $41.6 \pm 1.6$ \\
\hline МСH135.7 & $150 \pm 4$ & 18 & $2.96 \pm 0.12$ & 26 & $51 \pm 3$ \\
\hline МCH159.7 & $165 \pm 4$ & 37 & $1.84 \pm 0.10$ & 24 & $90 \pm 6$ \\
\hline MCH203.2 & $194 \pm 3$ & 36 & $2.00 \pm 0.11$ & 27 & $97 \pm 6$ \\
\hline HK 50.9 & $32.3 \pm 1.6$ & 18 & $2.39 \pm 0.08$ & 24 & $13.5 \pm 0.9$ \\
\hline HK 82.9 & $151 \pm \overline{2}$ & 39 & $2.21 \pm 0.12$ & 23 & $69 \pm \overline{4}$ \\
\hline HK83.6 & $143.9 \pm 1.8$ & 18 & $1.90 \pm 0.09$ & 21 & $76 \pm 4$ \\
\hline HK 101.0 & $163 \pm 3$ & 20 & $3.19 \pm 0.08$ & 25 & $51.2 \pm 1.9$ \\
\hline HK 136.3 & $138.7 \pm 1.8$ & 20 & $2.45 \pm 0.12$ & 19 & $57 \pm 3$ \\
\hline HK156.6 & $169 \pm \overline{3}$ & 20 & $2.45 \pm 0.39$ & 18 & $69 \pm 11$ \\
\hline HK179.9 & $181 \pm 3$ & 36 & $2.75 \pm 0.08$ & 26 & $66 \pm 3$ \\
\hline HK 199.0 & $219 \pm 5$ & 20 & $2.66 \pm 0.11$ & 31 & $82 \pm 4$ \\
\hline HK 212.2 & $188 \pm 3$ & 20 & $2.63 \pm 0.09$ & 32 & $72 \pm 3$ \\
\hline HK 243.5 & $204 \pm 2$ & 18 & $2.31 \pm 0.09$ & 29 & $88 \pm 4$ \\
\hline НК 249.7 & $207 \pm 4$ & 36 & $2.93 \pm 0.08$ & 23 & $71 \pm 3$ \\
\hline
\end{tabular}

\footnotetext{
${ }^{a}$ Standard errors calculated using results from ' $n$ ' aliquots.

${ }^{\mathrm{b}}$ Based on gamma spectrometry concentration results, converted to dose rates using its data of Olley et al. (1996), and cosmic ray contribution based on Prescott and Hutton (1988, 1994).

${ }^{\mathrm{c}}$ Water contents are measured after taking samples back to the laboratory and are assumed to be saturated since the depths for all samples are below the groundwater table.

${ }^{\mathrm{d}}$ The digits in the sample code indicate depth in metres.
}

prove that there is something wrong with these dose rates, the values of $D_{\mathrm{e}}$ do vary more smoothly down the core than the dose rates (see Table 2). Given the excellent luminescence characteristics of the material, it seems more likely that these anomalies arise because of errors in dose rate estimation. Despite these reservations, it is clear that a very large body of sediment (from 80 to $>250 \mathrm{~m}$ ) at this site (HK) was deposited in a relatively short time, $<40 \mathrm{ka}$. A similar conclusion can probably be drawn for site TY, but not at the intervening location $(\mathrm{MCH})$ where the corresponding period only records about $70 \mathrm{~m}$ of accumulation. This localised and massive accumulation is far more than can be accounted for by sea level fall leading to incision and subsequent filling, and must reflect spatially variable tectonic activity.
The late Quaternary history of the global sea-level change (Chappell and Shackleton, 1986; Martinson et al., 1987) is also used in Fig. 7 to demarcate the sedimentary sequence based on the sedimentary environmental change ( $\mathrm{Wu}, 1999)$ following the cycles of glacial and interglacial stages. The synchronous tie lines among the cores help us to differentiate the accumulations rate at each drilling site. The cores, $\mathrm{HK}, \mathrm{MCH}$, and TY, located in front of the Western Foothills, give different accumulation rates during the past several tens of thousand years. There data suggest the presence of a basement high at least at $\mathrm{MCH}$, implying a burial structure along the Pachenghsi; this correlates well with the recent investigations of tectonic lineate direction (Lacombe et al., 2001). From the distribution of deposits of Marine Isotope Stage (MIS) 2 (Fig. 7), the 


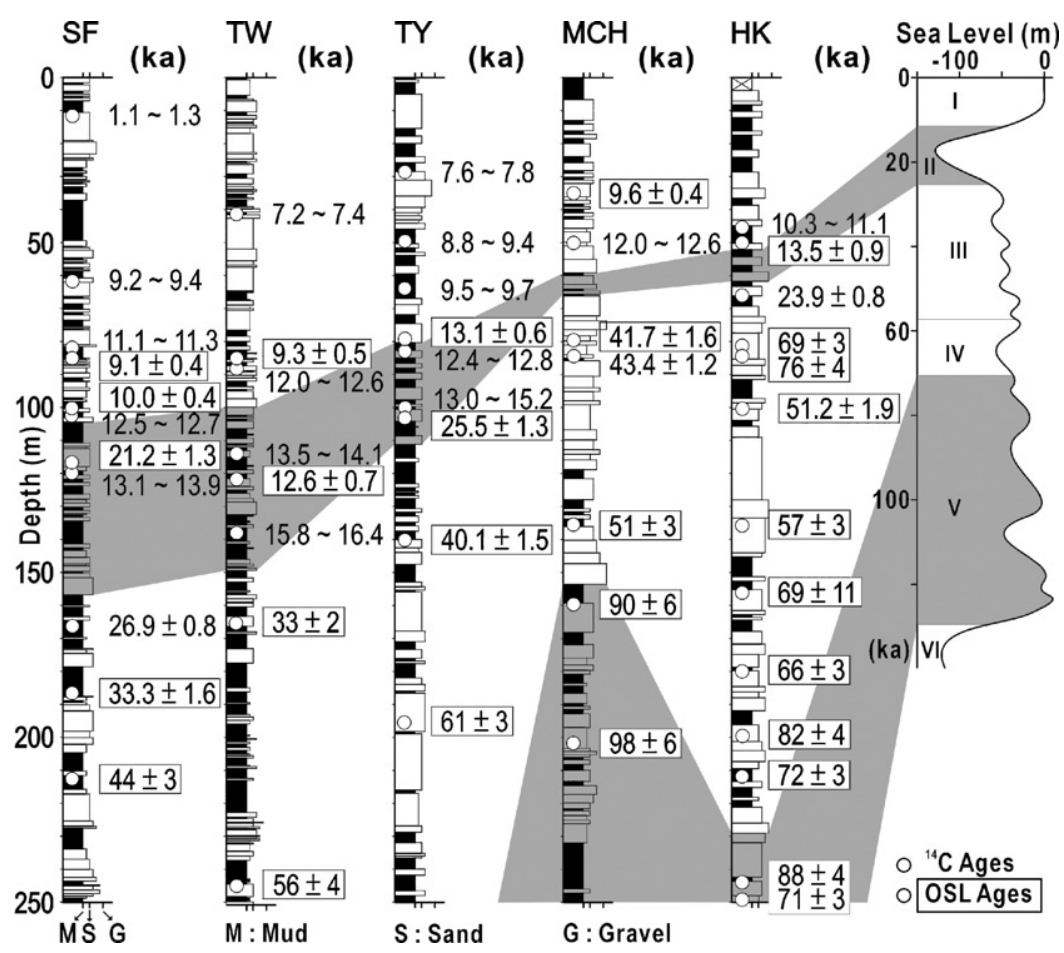

Fig. 7. Stratigraphic columns showing both luminescence and radiocarbon ages. The boxed ages were obtained using OSL, the remainder are ${ }^{14} \mathrm{C}$ ages, calibrated according to Stuiver and Reimer (1993). The width of the columns shows the grain size variations with depth OSL samples were taken from the sandy silts layers. It clears that the sandy silts were sampled in this study. The global sea-level change (Chappell and Shackleton, 1986) and the estimated ages of oxygen isotope stage boundaries (Matinson et al., 1987) are used to demarcate the sedimentary sequence.

Holocene depo-centre is probably further to the south of our study area.

\section{Conclusion}

It seems from our luminescence ages that OSL dating using SAR can be applied successfully to sediments from the western sedimentary basin in Taiwan. Quartz from these sediments is sensitive, and sensitivity changes can be corrected for using the response to a test dose. The apparent values of $D_{\mathrm{e}}$ are not sensitive to preheat or cutheat temperature, and the corresponding ages are credible, both based on internal tests, such as growth curves and dose recovery tests, and because, with one exception, the younger luminescence ages are consistent with ${ }^{14} \mathrm{C}$ results.

The thick layers of sediments accumulated during the Marine Isotope Stages (MIS) 1 and 3/4 show that sealevel change is not enough to create observed the large accumulation space, but subsidence movement is also necessary. Comparing the accumulation rate of the five cores studied here, the top of the Marine Isotope Stage (MIS) 3 is relatively down sloping southward and westward. Thus, it can be concluded that the foreland basin depo-centre is currently located to the southwest of the study area. On the other hand, the basement high found at $\mathrm{MCH}$ suggests that there might be a blind structure developed along Pachenghsi.

\section{Acknowledgements}

The authors would like to thank Dr. J.H. Choi of Seoul National University for his comments, and Miss M.F. Chu of National Taiwan University for help with the ICP-MS measurements. This study is financially supported by National Science Council, Republic of China under grant numbers of NSC89-2116-M-002-056 and NSC90-2119-M-002-009.

\section{References}

Bøtter-Jensen, L., Bulur, E., Duller, G.A.T., Murray, A.S., 2000. Advances in luminescence instrument systems. Radiation Measurements 32, 523-528.

Chappell, J., Shackleton, N.J., 1986. Oxygen isotopes and sea level. Nature 324, 137-140

Deffontaines, B., Lacombe, O., Angelier, J., Chu, H.T., Mouthereau, F., Lee, C.T., Deramond, J., Lee, J.F., Yu, M.S., Liew, P.M., 1997. Quaternary transfer faulting in the Taiwan Foothills: evidence from a multisource approach. Tectonophysics 274, 61-82.

Ho, C.S., 1982. Tectonic evolution of Taiwan. Ministry of Economic Affairs, Taipei, Taiwan, R.O.C., 126pp. 
Lacombe, O., Mouthereau, F., Angelier, J., Deffontaines, B., 2001. Structural, geodetic and seismological evidence for tectonic escape in SW Taiwan. Tectonophysics 333, 323-345.

Martinson, D.G., Pisias, N.G., Hays, J.D., Imbrie, J., Moore, T.C., Shackleton, N.J., 1987. Age dating and the orbital theory of the ice ages: development of a high resolution 0 to 300,000-year chronostratigraphy. Quaternary Research 27, 1-29.

Murray, A.S., Wintle, A.G., 2000. Luminescence dating of quartz using an improved single-aliquot regenerative-dose protocol. Radiation Measurements 32, 57-73.

Olley, J.M, Murray, A.S., Robert, R.G., 1996. The effects of disequilibria in the uranium and thorium decay chain on burial dose rates in fluvial sediments. Quaternary Science Reviews (Quaternary Geochronology) 15, 751-760.

Prescott, J.R., Hutton, J.T., 1988. Cosmic ray and gamma ray dosimetry for TL and ESR. Nuclear Tracks Radiation Measurements 14, 223-227.
Prescott, J.R., Hutton, J.T., 1994. Cosmic ray contribution to dose rates for luminescence and ESR dating: large depths and long-term time variations. Radiation Measurements 23, 497-500.

Rhodes, E.J., 2000. Observations of thermal transfer OSL signals in glacigenic quartz. Radiation Measurements 32, 595-602.

Stuiver, M., Reimer, P.L., 1993. Extended ${ }^{14} \mathrm{C}$ database and revised CALIB 3.0 ${ }^{14} \mathrm{C}$ age calibration program. Radiocarbon 35 , 215-230.

Teng, L.S., 1990. Geotectonic evolution of late Cenozoic arc-continent collision in Taiwan. Tectonophysics 183, 57-76.

Wintle, A.G., Murray, A.S., 2000. Quartz OSL: effects of thermal treatment and their relevance to laboratory dating procedure. Radiation Measurements 32, 387-400.

Wu, L.C., 1999. Analyses of sediment and depositional environments on the Chia-Nan Plain and stratigraphic correlation. Cent. Geol. Surv. Rept. 88-015, 119pp. (in Chinese). 